Clinical trial

\title{
A comparison of botanical and synthetic substances commonly used to prevent head lice (Pediculus humanus var. capitis) infestation
}

\author{
Deon V. Canyon, PhD, MPH, and Rick Speare, BVSc, MBBS, PhD
}

From the School of Public Health, Tropical Medicine and Rehabilitation Sciences, James

Cook University, Townsville, Qld, Australia

Correspondence

Deon V. Canyon, PhD, MPH,

School of Public Health,

Tropical Medicine and

Rehabilitation Sciences

James Cook University

Townsville, Qld 4811

Australia

E-mail: Deon.Canyon@jcu.edu.au

\begin{abstract}
Background Pediculosis, caused by head lice (Pediculidae: Pediculus humanus var. capitis), is experiencing a global resurgence, with the prevalence in primary schools averaging as high as $40 \%$ in some areas regardless of socioeconomic factors. Control efforts using chemical treatments are becoming increasingly ineffective, with insecticide resistance recorded in several countries. Prevention using repellents and oils would be useful if they limited transmission. Many commercially available substances reputedly have effective repellent qualities, but remain untested. Methods This study tested the preventative efficacy of $\mathrm{N}, \mathrm{N}$-diethyl-3-methylbenzamide (DEET) against several commercially available botanicals to clarify their value as transmission inhibitors, irritants, repellents, and antifeedants.

Results The transfer of head lice to treated hairs was limited by the slippery nature of the oils rather than their repellent qualities. Irritancy was not important because lice proceeded despite being highly irritated, except in the case of coconut. Tea tree and peppermint caused the most repellence, and tea tree and lavender prevented some blood feeding on treated skin.

Comparatively, tea tree oil was most efficacious, with DEET ranking equal second overall with coconut, peppermint, and a botanical mixture.

Conclusions Neither DEET nor any of the botanicals tested showed sufficient preventative

efficacy to be endorsed.
\end{abstract}

\section{Introduction}

For the past 9000 years, head lice (Pediculus humanus capitis De Geer), the causative organism of pediculosis, have evolved in close association with human hosts; ${ }^{\mathrm{I}}$ however, over the past decade, the status quo seems to have been disrupted. The global spread of pediculosis in both developing and developed countries, not as a result of socioeconomic factors, but because of increasing insecticide resistance, is well established. ${ }^{2}$ Many recent surveillance and control studies in northern Queensland, conducted by the Head Lice Research Group at James Cook University, Townsville, Queensland, Australia, have shown that $P$. capitis infestations in urban and rural primary schools are at a hyperendemic level (average prevalence of $20-40 \%) .{ }^{3}$ The mode of transmission is the subject of some debate and opinions are split on the importance of various mechanisms; ${ }^{4}$ however, the main source of infestation occurs at the classroom level, indicating clustering or close head-to-head contact as the primary cause. ${ }^{5}$

In northern Queensland, insecticide resistance in head lice is increasing rapidly. In $2000,50 \%$ resistance to permethrin was lice treatments had become ineffective, with $80 \%$ resistance to permethrin and $30 \%$ resistance to malathion-containing products (personal observation). Unfortunately, successful treatments are usually short lived as reinfection is almost guaranteed if associates of the treated person (and their associates) are not treated concurrently. Head lice are tolerant to a wide range of harsh environments [isopropyl alcohol (I00\%), salt (1०\%), chlorine ( $5 \mathrm{mg} / \mathrm{L})$, and vinegar ( $100 \%$ ) (personal observation)]. They are able to enter into a physiologically protective dormant condition or "stasis" for at least $20 \mathrm{~min}$ (average duration of most head lice treatments) during which they are impervious to most agents (personal observation).

Prevention using repellents or transmission inhibitors is thus an important option to reduce infestation opportunities. Most herbal remedy books promote the use of various preparations that can be applied to hair to prevent lice transmission. Essential oils from many of these herbs alone and in combination are available from most pharmacies and health shops. Unfortunately, the repellent effects associated with these oils are only reputed, and very few repellent trials on head lice have been published..$^{6-8}$ It is not known whether these substances prevent lice from colonizing a head by repelling lice or by 
making hair too slippery to grasp. More recently, Burkhart and Burkhart ${ }^{9}$ observed that head lice exhibited a clear dislike of piperonyl, garlic, and anise in combination with ylangylang and coconut carrier oils. This was thought to be an olfactory response.

This study thus aims to investigate the claims of several locally available "head lice repellents" and attempts to clarify the nature of their effect and quantify their preventative efficacy.

\section{Materials and Methods}

Obtaining fresh head lice for experiments is a time-consuming and unreliable affair, but necessary, as colonization is not possible without the apparatus described recently by Takano-Lee et al. ${ }^{10}$ Lice were supplied after they had been collected from a variety of households (ItchyHeads, Townsville, Qld, Australia).

Approximately 1420 late nymph/adult lice were used (Experiment 1, 440; Experiment 2, 440; Experiment 3, 340; total of 1220) plus 200 spare (total of 1420 lice required), as $15 \%$ mortality was expected when lice were removed from suitable hosts. Fresh lice were employed in each experiment as used lice carry residues from other repellents if they are used more than once. High mortalities (50-80\%) within 2 days of collection from a source were expected (personal observation).

The following essential oils and oil preparations were selected for experimentation because they were locally available and local anecdotal evidence supported their claims of efficacy. (i) Tea tree (Melaleuca alternifolia 100\%, Thursday Plantation Laboratories, Ballina); (ii) lavender (Lavandula angustifolia 100\%, The Perfect Potion, Virginio); (iii) peppermint (Mentha $\times$ piperita $100 \%$, Purity Australia, Byron Bay); (iv) coconut (Cocos nucifera 100\%, The Perfect Potion); (v) neem insect repellent [Azadirachta indica (neem) and Cymbopogon nardus (citronella), The Apothecary, Byron Bay]; (vi) scalp oil [Rosmarinus officinalis (rosemary), Laurus nobilis (bay), Cedrus atlantica (cedarwood), Pogostemon patchouli (patchouli), Cananga odorata (ylangylang), Simmondsia chinensis (jojoba), and Prunus armeniaca (apricot), The Perfect Potion]; (vii) Quitnit (Melaleuca alternifolia, Lavandula angustifolia, Rosmarinus officinalis, Cymbopogon nardus, and Azadirachta indica, The Apothecary, Midge Point); and (viii) Mix 4 (Cocos nucifera, Azadirachta indica, and Cymbopogon nardus).

$\mathrm{N}, \mathrm{N}$-Diethyl-3-methylbenzamide (DEET) $(69.75 \mathrm{~g} / \mathrm{L})$ was used as a positive control as it is the most powerful repellent yet discovered for a wide variety of arthropods. KY-Jelly, an inert lubricant gel, was used as a "slip" and irritant control, as it is possible that any reduction in transmission may be due, not to repellent effects, but to the slippery barrier caused by the oil on the hair, or odour, or simply the presence of a foreign substance.

\section{Experiment 1 - transmission inhibition}

In Experiment 1, each louse (20 replicates) was placed on a stationary suspended hair and was presented with a mobile repellent-treated hair for transmission. All hair passes involved contact between the uninhabited hair and the lice. Mobile hairs were presented laterally from tail to head at a speed of $4 \mathrm{~m} / \mathrm{min}$. ${ }^{4}$ The transmission inhibition potential was assessed by recording the number of lice that transferred from the stationary hair onto the mobile treated hair.

\section{Experiment 2 - irritancy}

In Experiment 2, irritancy was assessed by placing lice (20 replicates) in the center of a suspended hair. The ends of the hair were coated in the phytochemical or control substance under investigation. Lice behavior was observed and four responses were noted: tropotaxis (avoidance) - refusal to walk onto the treated portion of the hair; tropotaxis (hesitation - lice walk onto the treated section but with some hesitation or reverse; orthokinesis - speed of progress whilst on the treated portion; and klinokinesis (confusion) - assessed by noting the number of about-turns. Each of these responses was ranked from normal to mild to strong in its observed effect.

\section{Experiment 3 - avoidance}

In Experiment 3, circles of skin (2.5 cm in diameter) on Canyon's forearms were marked out and test materials were applied to them with a well-soaked cotton bud. After 2 min, lice (15 replicates) were placed onto the treated areas. Observations of lice behavior included avoidance behavior (lice leaving the treated region), antifeedant behavior (lice remaining on the treated area but failing to feed), and failure of repellent (lice biting).

\section{Results}

In Experiment I, the overall model was not significant (chisquared exact $P>0.05$ ); however, a clear trend was observed (Fig. I). The coconut-neem-citronella mixture was most effective and prevented $65 \%$ of all transmission attempts. The neem-citronella mixture only prevented $33 \%$ of transmission attempts, which was well below KY-Jelly, the "slip" control, which prevented just over $42 \%$.

In Experiment 2, the overall model was significant (chisquared exact $P<0.05$ ) (Fig. 2 ). Tropotaxis in response to contact with treated hair was minimal for all test substances, except coconut oil, which was more viscous. Neem, citronella, and DEET produced the next best responses. Head lice did not hesitate or seek to avoid tea tree, peppermint, lavender, and scalp oil to any significant extent. The results for orthokinesis and klinokinesis were fairly similar, with most test substances causing a decrease in the speed of progress. Coconut, neem, and scalp oil performed the best, but lavender and peppermint did not perform well. When all measures of irritancy (tropotaxis, orthokinesis, and klinokinesis) were pooled, the Kruskal-Wallis model showed a significant difference $(P<O . \circ \mathrm{I})$, with coconut emerging as a clearly superior irritant.

In Experiment 3, the overall model was significant (chisquared exact $P<0.05$ ). Most repellents were not effective at 


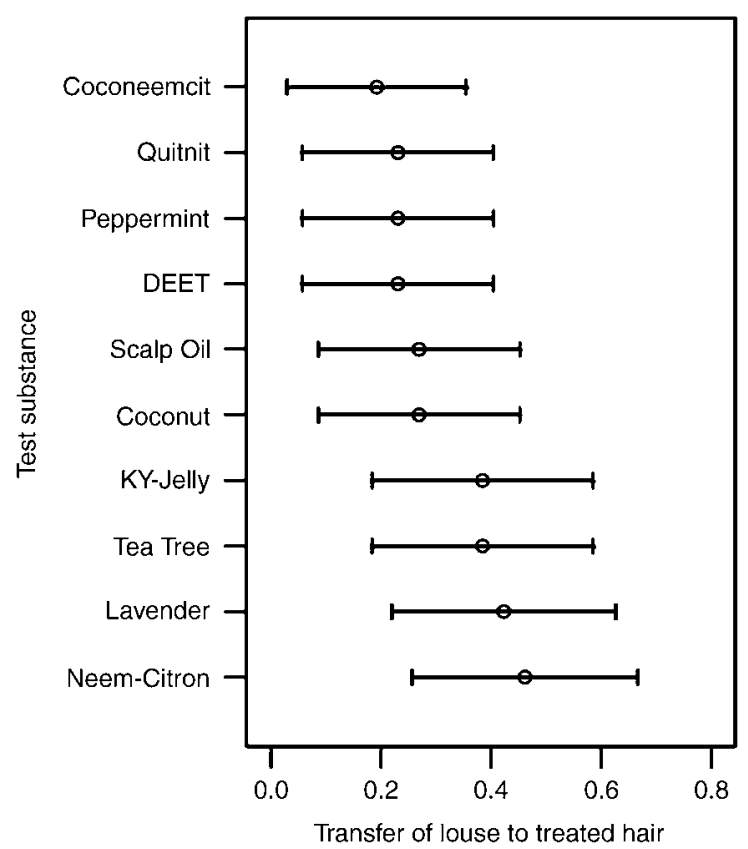

$(95 \% \mathrm{Cl})$

Figure 1 Efficacy of test substances in preventing louse transmission from one hair to another. A value of unity indicates that all lice transferred successfully. DEET, N,N-diethyl-3methylbenzamide

causing lice to leave the treated site or at preventing blood feeding (Figs 3 and 4 ). Tea tree oil, which repelled $55 \%$ of head lice from the treated area, was the most effective repellent, followed by peppermint ( $34 \%$ ) and DEET ( $26 \%)$. Neem products did not show any repellent action. When antifeedant qualities were assessed, tea tree was again the most effective, preventing $60 \%$ of lice from feeding, followed by lavender $(40 \%)$, peppermint $(28 \%)$, and DEET ( $23 \%)$. Neem, citronella, and coconut products did not prevent feeding.

\section{Discussion}

With the increasing global prevalence of pediculosis and accompanying increasing awareness, the number of head lice repellents and preventatives available over the counter has increased dramatically without any quality assurance or control. Although synthetic chemicals require scrutiny before they reach the market, phytochemicals are not covered by the United States Environmental Protection Agency (USEPA) legislation, and require no testing for either efficacy or toxicity.

This study found that all substances tested were nonefficacious as head lice repellents, with only a marginal level of activity demonstrated (Table I). Comparatively, several botanical substances were equally as effective as DEET, with tea tree being a superior repellent and antifeedant. Although

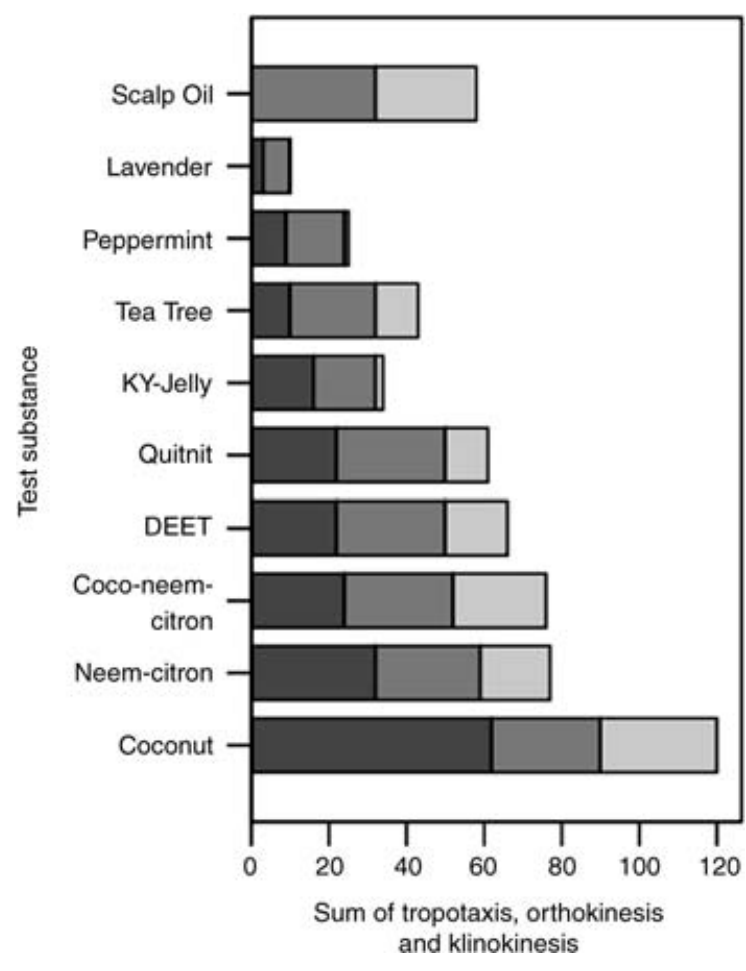

Figure 2 Efficacy of test substances as irritants, causing tropotaxis (dark gray), orthokinesis (gray), and klinokinesis (light gray) in lice encountering the substance whilst proceeding down a hair. DEET, N,N-diethyl-3-methylbenzamide

the substances reduced transmission to a treated hair by $33-65 \%$, most of this effect was due to the slippery nature of treated hair, as demonstrated by the KY-Jelly response. This perhaps explains why head lice are more prevalent in "clean hair" heads than in "greasy" heads.

The value of the irritant response was questionable as most lice progressed forwards despite showing some tropotaxis, except with coconut. Neem and citronella were not significant irritants and reduced the irritancy of coconut when combined.

DEET performed well overall in a comparative sense; however, it was outdone by tea tree and peppermint in Experiment 3. Tea tree, despite having no adverse effect on lice transfer and not being an irritant, was most effective at repelling and reducing blood feeding. Over half of the head lice transferring to a tea tree-treated head would thus be expected to transfer out as soon as possible and, failing that, would be less inclined to survive as blood meals would be inhibited. This is positive news as it is not advisable to apply DEET on a regular basis to the scalp. Other combinations involving tea tree, peppermint, and coconut may prove to be more effective. Lavender, a common ingredient in head lice preventative preparations, is only useful in limiting blood feeding, but may help to tone down the strong smells of the other substances. 


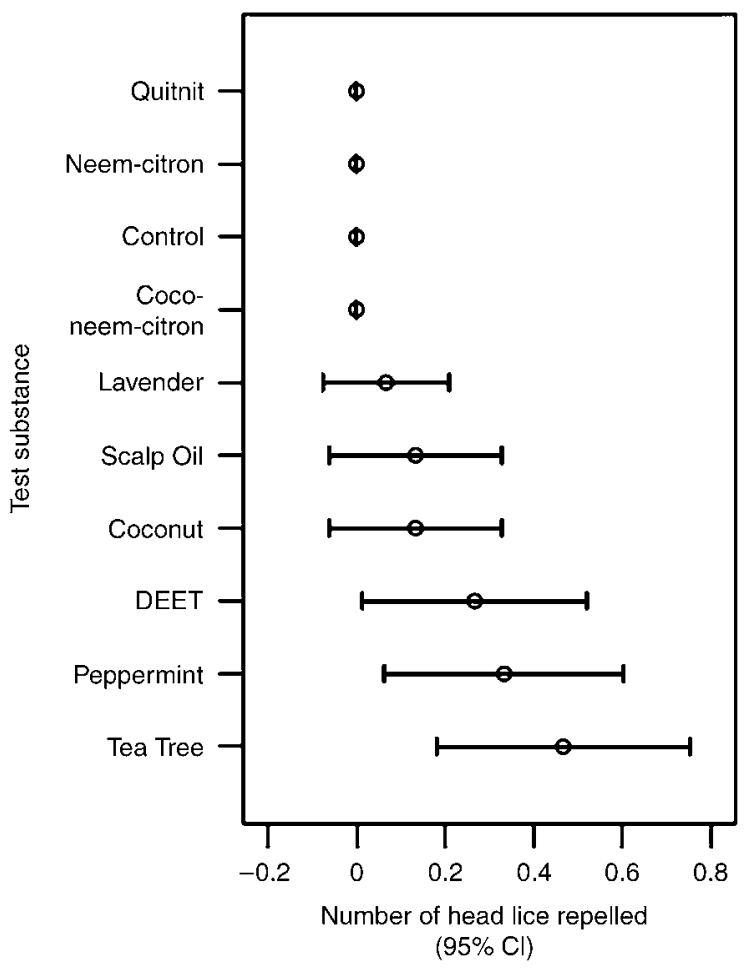

Figure 3 Efficacy of test substances in causing lice to leave the treated site. A value of unity indicates that all lice were repelled from the treated skin. DEET, N,N-diethyl-3-methylbenzamide

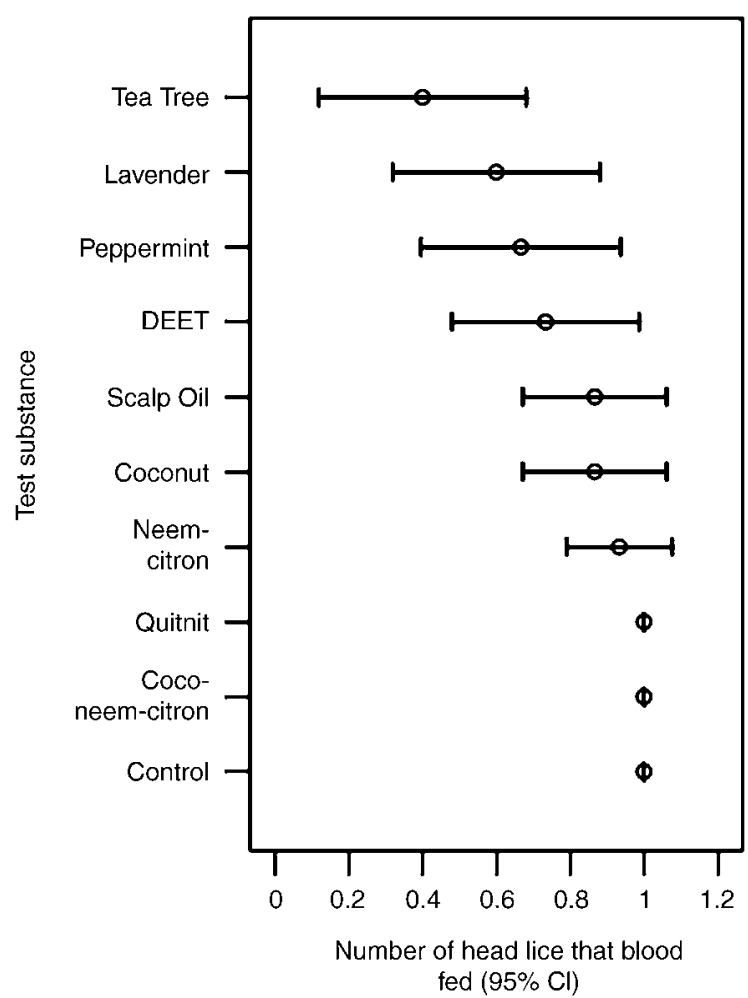

Figure 4 Efficacy of test substances in preventing blood feeding. A value of unity indicates that all lice took a blood meal on the treated skin. DEET, N,N-diethyl-3-methylbenzamide

Table 1 Comparative summary of overall test substance efficacy against head lice in various experimental conditions involving transmission, irritancy, repellence, and antifeedance. Effects due to controls and not to repellent are given in bold type

\begin{tabular}{|c|c|c|c|c|c|}
\hline \multirow[b]{2}{*}{ Test substance } & \multicolumn{4}{|c|}{ Extent of response } & \multirow[b]{2}{*}{ Sum } \\
\hline & $\begin{array}{l}\text { Exp. 1: } \\
\text { prevent transfer }\end{array}$ & $\begin{array}{l}\text { Exp. 2: } \\
\text { cause irritancy }\end{array}$ & $\begin{array}{l}\text { Exp. 3: } \\
\text { cause repellence }\end{array}$ & $\begin{array}{l}\text { Exp. 3: } \\
\text { prevent feeding }\end{array}$ & \\
\hline Tea tree & $\mathbf{X X}^{\star}$ & $x x$ & $X X X X X$ & $X X X X X X$ & 12 \\
\hline Peppermint & $\mathbf{x x X X}$ & $\mathbf{x}$ & $X X X X$ & $X X X X$ & 10 \\
\hline Coconut & $\mathbf{x x x}$ & $X X X X X X$ & $x x$ & $x x$ & 10 \\
\hline$N, N$-Diethyl-3-methylbenzamide (DEET) & $x x \times x$ & $\mathrm{XXX}$ & $x x x$ & $x X X$ & 10 \\
\hline $\begin{array}{l}\text { Scalp oil - rosemary, bay, cedarwood, } \\
\text { patchouli, ylangylang, jojoba, apricot }\end{array}$ & $x \mathbf{x x}$ & $X X X X$ & $x x$ & $x x$ & 8 \\
\hline Lavender & $\mathbf{x x}$ & & $x$ & $x X X X X$ & 6 \\
\hline Coconut-neem-citronella & $x x x x x$ & $X X X X$ & $-\dagger$ & - & 6 \\
\hline $\begin{array}{l}\text { Quitnit - tea tree, lavender, } \\
\text { rosemary, citronella, neem }\end{array}$ & $x x x x$ & $x X X$ & - & - & 4 \\
\hline Neem-citronella & $\mathbf{x}$ & $x X X$ & - & $x$ & 3 \\
\hline KY-Jelly (slip control) & $\mathbf{x x}$ & $\mathbf{x}$ & $\mathrm{n} / \mathrm{a}$ & $\mathrm{n} / \mathrm{a}$ & $\mathrm{n} / \mathrm{a}$ \\
\hline Control (no skin treatment) & $\mathrm{n} / \mathrm{a}$ & $\mathrm{n} / \mathrm{a}$ & All stayed & All fed & $\mathrm{n} / \mathrm{a}$ \\
\hline
\end{tabular}

$\mathrm{n} / \mathrm{a}$, not applicable.

"Bold X represents the extent to which control factors contribute to the total response and is not calculated in the "Sum".

†No observable response. 
Any application of repellent or other preventative in infested individuals may act to increase the dispersal of head lice to other contacts in social groups or family. Head lice are thought to view people's heads as "rooms" in their "home," rather than viewing a head as a permanent abode (personal observation). Core social groups in classrooms probably facilitate this behavior. Increased dispersal within the core group would thus cause a more rapid change of rooms with greater potential to infest subsidiary contact groups. Therefore, the application of preventatives to all subsidiary groups and family would be beneficial if combined with identification and thorough treatment of all core group members.

\section{Acknowledgment}

We gratefully acknowledge the provision of freshly caught head lice from Ms Chris Cahill (ItchyHeads), Townsville, Qld, Australia.

\section{References}

I Mumcuoglu KY, Zias J. Head lice, Pediculus humanus capitis (Anoplura: Pediculidae), from hair combs excavated in Israel and dated from the first century B.C. to the eighth century A.D. J Med Entomol I988; 25: 545-547.

2 Gratz NG. Human Lice: Their Prevalence, Control and Resistance to Insecticides. A Review 1985-1997. Geneva: World Health Organization, 1997.

3 Speare R, Buettner P. Hard data needed on head lice transmission. Int J Dermatol 2000; 39: 877-878.

4 Canyon DV, Speare R, Muller R. Spatial and kinetic factors for the transfer of head lice (Pediculus capitis) between hairs. J Invest Dermatol 2002; II9: 629-63I.

5 Speare R, Buettner PG. Head lice in pupils of a primary school in Australia and implications for control. Int J Dermatol 1999; 38: 285-290.

6 Burgess I. New head louse repellent. Br J Dermatol I993; I28: $357-358$.

7 Peock S, Maunder JW. Arena tests with piperonal, a new louse repellent. J R Soc Health I993; II 3: 292-294.

8 Ibarra J, Williams B. Head louse repellents. J R Soc Health I994; II4: 108.

9 Burkhart CG, Burkhart CN. Clinical evidence of lice resistance to over-the-counter products. J Cutan Med Surg 2000; 4: I99-2OI.

Io Takano-Lee M, Velten RK, Edman JD, et al. An automated feeding apparatus for in vitro maintenance of the human head louse, Pediculus capitis (Anoplura: Pediculidae). J Med Entomol 2004; 40: 795-799. 